\title{
O ESTÁGIO SUPERVISIONADO EM MATEMÁTICA COMO ESPAÇO DE DESENVOLVIMENTO DA EPISTEMOLOGIA DA PRÁTICA DOCENTE
}

\author{
Francisco José de Lima ${ }^{1}$ \\ Instituto Federal de Educação, Ciência e \\ Tecnologia do Ceará
}

Isaías Batista de Lima

Universidade Estadual do Ceará

\begin{abstract}
Resumo
O presente artigo propõe discutir o Estágio Supervisionado como espaço de elaboração e desenvolvimento de uma epistemologia da prática, com vistas à compreensão da docência em matemática. Por meio de pesquisa qualitativa arrimada, num estudo bibliográfico e documental, em apresentam-se experiências educativas vivenciadas por ocasião da execução didático-pedagógica do currículo do Curso de Licenciatura em Matemática do Instituto Federal de Educação, Ciência e Tecnologia do Ceará - campus Cedro. Esse currículo foi implantado no semestre 2009.2, com licenciandos em matemática. Todo o material para a análise foi coletado por meio de observações feitas e registradas a partir de debates em sala de aula, registros escritos e relatórios finais da disciplina. Os significados atribuídos ao estágio revelam a importância da mediação realizada no decorrer das atividades desenvolvidas pelo professor-orientador, pelas teorias elencadas na matriz curricular do curso, bem como da colaboração dos professores das escolas, para que a experiência de estágio seja significativa e prepare o futuro professor para encarar com sabedoria os primeiros anos de exercício na docência. $\mathrm{O}$ resultado da pesquisa demonstrou que o estágio oportunizou aos estagiários desenvolver uma epistemologia da prática docente para o exercício da profissão, em que a análise, a articulação e a reflexão crítica lhes possibilitaram assumir posturas diferenciadas em relação à prática tradicional e conteudista de ensino em matemática.
\end{abstract}

Palavras-chave: Estágio supervisionado; Saber docente; Docência em Matemática.

\footnotetext{
1 Licenciado em Pedagogia e em Matemática, Especialista em Metodologia e Funcionamento do Ensino Fundamental e Médio e em Gestão Escolar, Mestre em Ensino de Ciências e Matemática pela Universidade Federal do Ceará (UFC), Professor do Instituto Federal de Educação, Ciência e Tecnologia do Ceará (IFCE) campus Cedro. franciscojose@ifce.edu.br

${ }^{2}$ Licenciado e bacharel em Filosofia, Especialista em Filosofia Política. Mestre e Doutor em Educação pela UFC, Professor Adjunto da Universidade Estadual do Ceará (UECE). Professor colaborador do Mestrado em Ensino de Ciências e Matemática da UFC/ENCIMA. Líder do grupo de Pesquisa FIMEPE. Pesquisador bolsista BPI/FUNCAP. isaias.lima@uece.br
}

Olh@ res, Guarulhos, v. 1, n1, p. 303-324, maio 2013. 


\title{
THE SUPERVISED INTERNSHIP IN MATHEMATICS AS DEVELOPMENT SPACE OF EPISTEMOLOGY OF TEACHING PRACTICE
}

\begin{abstract}
This article proposes to discuss the supervised internship as a space of elaboration and development of an epistemology of practice, with a view to understanding of teaching in mathematics. Through qualitative research, arrimada on a documentary and bibliographical study in educational experiences are experienced on the occasion of the implementation of the curriculum of didactic-pedagogical course degree in mathematics of the Instituto Federal de Educação, Ciência e Tecnologia do Ceará - Cedro campus. This curriculum was implemented in the first half, 2009.2 with licenciandos in mathematics. All the material for the analysis was collected through observations made and recorded from class discussions, written records and final reports. The meanings assigned to the stage show the importance of mediation carried out in the course of the activities developed by the professor-tutor, listed theories in the course curriculum, as well as the collaboration of teachers from schools, so that the stage is significant experience and prepare the future professor to take wisdom early exercise in teaching. The result of the research showed that the stage "provided to the trainees develop an epistemology of teaching practice for the practice of the profession, in that analysis, the articulation and critical reflection enabled them to assume different postures in relation to traditional practice and teaching concepts in mathematics.
\end{abstract}

Keywords: Supervised internship; Know teacher; Teaching in mathematics. 


\section{Introdução}

Este artigo tem por finalidade analisar e discutir o Estágio Supervisionado como espaço de aprendizagem, entendido como relevante na formação inicial de professores e possibilitador da construção de caminhos para o exercício da docência em matemática. Sendo assim, tomou-se como referência, estudos que apontam o estágio como "eixo central nos cursos de formação de professores, ao trazer a possibilidade de se trabalhar aspectos indispensáveis à construção do ser profissional docente no que se refere à construção da identidade, dos saberes e das posturas necessárias" (PIMENTA \& LIMA, 2012, p. 29 ).

No contexto da legislação educacional brasileira, o Estágio Supervisionado é obrigatório para a conclusão dos cursos de licenciatura. O Conselho Nacional de Educação por meio do Parecer $n^{\circ}$ 28/2001, especifica a licenciatura como uma condição para o exercício de uma atividade docente. Essa obrigatoriedade aponta para a necessidade de se tomar a atividade docente e seu exercício, como conditio sine qua non para a própria formação intelectual e prática pedagógica do futuro professor, o que requer orientação e acompanhamento de um profissional já habilitado que, por sua vez, toma a práxis docente com um espaço de saberes em trânsito, logo inacabado.

Diante disso, o estágio curricular supervisionado deve ser compreendido como tempo de aprendizagem e, consequentemente, espaço para a produção de conhecimentos da atividade docente. Portanto, "supõe uma relação pedagógica entre alguém que já é profissional reconhecido em um ambiente institucional de trabalho e um aluno estagiário" (CNE/CP 28/2001 BRASIL, 2001, p. 2). Com as atividades de estágio desenvolvidas no Curso de Licenciatura em Matemática do IFCE, Campus Cedro, compreende-se que o exercício da profissão docente constitui-se de saberes teóricos e práticos que se interceptam e se fundem na práxis do professor, permitindo compreender a indissociabilidade existente entre teoria e prática. No Parecer CNE/CP 28/2001, encontram-se os fundamentos que dialogam sobre teoria

Olh@ res, Guarulhos, v. 1, n1, p. 30-324, maio 2013. 
e prática no e para o estágio, fortalecendo a compreensão de unidade na diferença entre estes momentos da atividade docente.

A prática não é uma cópia da teoria e nem esta é um reflexo daquela. A prática é o próprio modo como as coisas vão sendo feitas cujo conteúdo é atravessado por uma teoria. Assim a realidade é um movimento constituído pela prática e pela teoria como momentos de um dever mais amplo, consistindo a prática no momento pelo qual se busca fazer algo, produzir alguma coisa e que a teoria procura conceituar, significar e com isto administrar o campo e o sentido desta atuação. (CNE/CP 28/2001, p. 9).

Desse modo, os referenciais teóricos que se reportam à formação de professores tem dado ênfase ao Estágio, como componente curricular importante na formação inicial do professor, porém se tem também evidenciado a existência de limitações e falhas nesse processo de construção de saberes sobre a práxis docente. De acordo Zeichner (2010, p. 482),

[...] a desconexão entre a formação de professores no âmbito acadêmico e nas escolas tem sido um problema perene (Vick, 2006). Já tem sido claramente documentada há muitos anos (por exemplo, Clifford \& Guthrie, 1988; Goodlad, 1990; Labaree, 2004), que existem poucos incentivos para professores efetivos investirem algum tempo na coordenação entre os componentes acadêmicos e os que ocorrem a campo na formação de professores e, sobretudo, para tutorar e monitorar o trabalho dos supervisores a campo.

Como alternativa para minimizar esses descompassos Zeichner (2010) aponta a criação de terceiros espaços, os quais constituiriam novas formas para aprimorar a aprendizagem dos futuros professores. Esses espaços seriam contrários à desconexão tradicional entre escola e universidade e “[...] reúnem o conhecimento prático ao acadêmico de modos menos hierárquicos, tendo em vista a criação de novas oportunidades de aprendizagem para professores em formação" (ZEICHNER, 2010, p. 487).

A partir das reformas ocorridas no âmbito educacional, a formação inicial do professor tem ganhado espaço no universo das discussões e reflexões que se travam na busca por melhorias na qualidade do ensino. Assim, Barreiro \& Gebran (2006, p. 22) afirmam que:

[...] a formação inicial é o começo da busca de uma base para o exercício da atividade docente. [...] deve assentar-se em concepções e práticas que levem à reflexão, no sentido de promover saberes da experiência, conjugados com a teoria, permitindo ao professor uma análise integrada e sistemática da sua ação educativa de forma investigativa e interventiva.

Nesse sentido, o estágio surge como um caminho para a formação inicial do futuro professor, sendo a forma de enriquecer o fazer docente tomado como um relevante momento da formação inicial do professor, em que o graduando pode vivenciar experiências diversas da profissão docente, co-

Olh@ res, Guarulhos, v. 1, n1, p. 303-324, maio 2013. 
nhecendo melhor a área que atuará como profissional. Sendo assim, o estágio propicia interação entre os cursos de formação e o contexto social no qual está situada a escola, enquanto lócus onde se desenvolvem as práticas educativas.

A observação da prática do professor representa uma rica fonte de elementos da realidade para subsidiar a discussão e a reflexão entre professores-orientadores e os professores em formação, produzindo e disseminando conhecimento sobre prática de ensino, propício à formação inicial de professores, tecendo saberes para o campo educacional e sua complexidade.

[...] ao transitar da universidade para a escola e desta para a universidade, os estagiários podem tecer uma rede de relações, conhecimentos e aprendizagens, não com o objetivo de copiar, de criticar apenas os modelos, mas no sentido de compreender a realidade para ultrapassá-la. Aprender com os professores de profissão como é o ensino, como é ensinar, é o desafio a ser aprendido/ensinado no decorrer dos cursos de formação e no estágio. (TARDIF, 2002, p. 295)

O Estágio Supervisionado consolida-se na tentativa de contribuir com o processo de formação do professor e o desenvolvimento de uma epistemologia da prática profissional, enquanto propagação de um conjunto de saberes que serão utilizados pelo professor no exercício da docência. A epistemologia da prática tem por finalidade

[...] revelar esses saberes, compreender como são integrados concretamente nas tarefas profissionais e como estes os incorporam, produzem, utilizam, aplicam e transformam em função dos limites e dos recursos inerentes às suas atividades de trabalho. Visa compreender também, a natureza desses saberes, assim como o papel que desempenham tanto no processo de trabalho docente quanto em relação à identidade profissional do professor. (TARDIF, 2002, p. 256)

Para Pimenta e Lima (2012, p. 55), “[...] o estágio então deixa de ser considerado apenas um dos componentes e mesmo um apêndice do currículo e passa a integrar o corpo de conhecimentos do curso de formação de professores". Isso porque o contexto educacional vigente exige profissionais que estejam preparados para lidar com as diversas realidades que se interpenetram dialeticamente no contexto escolar. É a partir da realização do estágio que o estagiário - futuro professor de matemática adquire experiência e busca novas maneiras de atuar em sala de aula,

Olh@ res, Guarulhos, v. 1, n1, p. 30-324, maio 2013. 
(re)pensando sempre a prática docente e aprimorando seus conhecimentos para melhor desenvolver sua ação profissional.

A ação do educador pode ser associada à atividade do artesão, isto é, à atividade de alguém, que: 1) possui uma ideia, uma representação geral do objetivo que quer atingir; 2) possui um conhecimento adquirido e concreto sobre o material com o qual trabalha; 3) age baseando-se na tradição e em receitas de efeito comprovado específicas à sua arte; 4) age fiando-se também em sua habilidade pessoal, e, finalmente, 5) age guiando-se por sua experiência, fonte de bons hábitos, isto é, de "maneiras-de-fazer", de "truques", de "maneiras-de-proceder" comprovadas pelo tempo e pelos êxitos sucessivos. (TARDIF, 2002, p.159)

Estas experiências darão ao licenciando oportunidade de estabelecer contato com o contexto escolar e conhecer todas as dimensões do trabalho desenvolvido pela instituição, bem como acompanhar a dinâmica das ações educativas desenvolvidas no cotidiano escolar. É neste universo de preparação para o exercício da docência, que o professor em formação inicial deverá compreender que o fazer docente "exige tomada consciente de decisão" (FREIRE, 1996, p. 122) e saberes necessários para o desenvolvimento da prática educativa.

Assim, o Estágio Supervisionado enquanto prática de ensino deve propiciar ao professor em formação inicial o desenvolvimento de saberes indispensáveis ao seu trabalho. Dessa forma, faz-se necessário ter conhecimento da matéria a qual se propõe a ensinar; saber dirigir e organizar atividades de ensino; administrar a sala de aula; conhecer o contexto social no qual está situada a instituição de ensino; utilizar diferentes metodologias de ensino e saber avaliar. Logo, saberes capazes de potencializar, para melhor, a sua práxis.

O estágio configura-se como oportunidade única para que o futuro professor compreenda a dinâmica e as facetas do universo da profissão que o profissional está se propondo integrar, ao permitir o confronto dialético entre a teoria e a prática. No desenvolvimento da atividade docente, o professor deve aprender com sua própria prática e com as experiências vividas com seus pares no fazer pedagógico da sala de aula e da escola. O professor deve conceber a sala de aula, como um espaço de aprendizagem permanente, pois enquanto sujeito do conhecimento, este deve refletir sobre

Olh@res, Guarulhos, v. 1, n1, p. 303-324, maio 2013. 
o seu processo de formação profissional, apreendendo-o e redimensionando-

o no intercâmbio dos diversos saberes que permeia o fazer docente.

Tardif (2008) apresenta as características do conhecimento profissional, conforme exposto no quadro a seguir:

Quadro 01 - Principais características do conhecimento profissional

\begin{tabular}{|c|l|}
\hline $\mathbf{N}^{\mathbf{0}}$ & \multicolumn{1}{|c|}{ Características } \\
\hline 1 & $\begin{array}{l}\text { Em sua prática, os profissionais devem se apoiar em conhecimentos especializados e formalizados, na } \\
\text { maioria das vezes, por intermédio das disciplinas científicas em sentido amplo, incluindo, } \\
\text { evidentemente, as ciências naturais e aplicadas, mas também as ciências sociais e humanas, assim } \\
\text { como as ciências da educação. }\end{array}$ \\
\hline 2 & $\begin{array}{l}\text { Esses conhecimentos especializados devem ser adquiridos através de uma longa formação de alto } \\
\text { nível, na maioria das vezes, de natureza universitária ou equivalente. [...]. }\end{array}$ \\
\hline 3 & $\begin{array}{l}\text { Embora possam se basear em disciplinas científicas ditas "puras”, os conhecimentos profissionais são } \\
\text { essencialmente pragmáticos, ou seja, são modelados e voltados para a solução de situações } \\
\text { problemáticas concretas, [...]. }\end{array}$ \\
\hline 4 & $\begin{array}{l}\text { Em princípio, só os profissionais, [...], possuem a competência e o direito de usar seus conhecimentos, } \\
\text { [...] eles pertencem legalmente a um grupo que possui o direito exclusivo de usá-los por ser, em } \\
\text { principio, o único a dominá-los e a poder fazer uso deles. }\end{array}$ \\
\hline 5 & $\begin{array}{l}\text { Isso significa também que só os profissionais são capazes de avaliar, em plena consciência, o trabalho } \\
\text { de seus pares. [...]. }\end{array}$ \\
\hline 6 & $\begin{array}{l}\text { Esses conhecimentos exigem também autonomia e discernimento por parte dos profissionais, ou seja, } \\
\text { não se trata somente de conhecimentos técnicos padronizados cujos modos operatórios são codificados } \\
\text { e conhecidos de antemão, [...]. }\end{array}$ \\
\hline 7 & $\begin{array}{l}\text { [...] os conhecimentos profissionais são evolutivos e progressivos e necessitam, por conseguinte, de } \\
\text { uma formação continua e continuada. [...]. }\end{array}$ \\
\hline 8 & $\begin{array}{l}\text { Enfim, os profissionais podem ser considerados responsáveis [...] pelo mau uso de seus conhecimentos, } \\
\text { causando, desse modo, danos a seus clientes. [...]. }\end{array}$ \\
\hline
\end{tabular}

Fonte: Formatação nossa a partir de Tardif (2002, p. 247-249).

Nesse contexto, pensar no estágio como espaço/tempo de aprendizagem da docência é visualizar a indissociabilidade existente entre teoria e prática no desenvolvimento de saberes necessários à prática educativa, permitindo ao professor em formação inicial compreender a complexidade do ofício e possibilidade de ensinar e aprender por meio do exercício da profissão. Por isso, Wielewicki (2010, p. 31) afirmar que:

É preciso reconhecer, portanto, que o desenvolvimento profissional docente (seja na universidade ou na escola) exige agência (isto é, participação ativa, comprometida e diligente) dos professores, não só por serem impactados diretamente por esse processo, mas especialmente pelo fato de que ao se assumirem sujeitos de sua formação, os professores avançam na direção de sua emancipação intelectual.

\section{Caminhos metodológicos}

Enquanto pesquisa qualitativa, esta se constituirá de diálogos entre literatura pertinente, legislação oficial e conteúdo de depoimentos de sujeitos envol-

Olh@ res, Guarulhos, v. 1, n1, p. 30-324, maio 2013. 
vidos em seu fazer educativos. Como referência, elencou-se o Estágio Supervisionado do Curso de Licenciatura em Matemática do IFCE/Campus Cedro, o qual está pautado em princípios legais e visa possibilitar aos futuros professores condições para o exercício da docência, mediante o desenvolvimento das aptidões requeridas para esse exercício, levando-os a vivenciar experiências durante o processo de formação.

O IFCE/Campus Cedro, por meio de sua proposta pedagógica para a formação de professores de Matemática, busca preparar profissionais para o exercício crítico e competente para o exercício da docência no Ensino Fundamental e Médio com embasamento teórico-prático de modo a contribuir para a melhoria do desenvolvimento da Educação Básica da nossa região. De acordo com essa proposta, são objetivos do curso:

Capacitar professores para compreender a ciência como atividade humana contextualizada e como elemento de interpretação e intervenção no mundo; Entender a relação entre o desenvolvimento de Ciências Naturais e o desenvolvimento tecnológico e associar as diferentes tecnologias à solução de problemas; Utilizar elementos e conhecimentos científicos e tecnológicos, particularmente, alguns conteúdos básicos para entender e resolver as questões problemáticas da vida cotidiana; Compreender e aplicar métodos e procedimentos próprios utilizados pelas disciplinas da área; Elaborar projetos para o Ensino Fundamental ( $6^{\circ}$ ao $9^{\circ}$ ano) e para o Ensino Médio baseados nos novos parâmetros curriculares nacionais articulados com a realidade vivenciada. (IFCE/Campus Cedro, 2007, p.17).

Verifica-se, portanto, que a Proposta Pedagógica do Curso de Licenciatura em Matemática do IFCE/Campus Cedro está assentada na perspectiva da formação humana e contempla as dimensões humanista e crítica. Nesse sentido, o Estágio Supervisionado tem por finalidade propiciar ao aluno uma aproximação da realidade, em que a aprendizagem se efetiva, apontando para algumas características, como responsabilidade, compromisso e espírito crítico e inovador.

Vale ressaltar que o estágio é parte integradora do currículo dos cursos de formação de professores, compreendido como o momento em que o licenciando vai assumir pela primeira vez o contato prático com a docência e as mediações societária do contato com o aluno, com a instituição escolar que representa o processo de socialização primária e inclusão do homem no processo civilizatória, com a produção conjunta de significados sobre o mundo. Nesse contexto, o fazer docente adquire o caráter de profissionalida-

Olh@ res, Guarulhos, v. 1, n1, p. 303-324, maio 2013. 
de, que implique competência - fazer bem o que lhe compete. (ANDRADE, 2005).

O Estágio do Curso de Licenciatura em Matemática do IFCE/Campus Cedro tem suas atividades distribuídas a partir do quinto semestre e divide-se em quatro componentes curriculares:

- O Estágio I - exercido no Ensino Fundamental, e;

- O Estágio III - exercido no Ensino Médio.

Ambos são estágios marcados pela observação e participação no exercício da docência. Pimenta e Lima (2006) apontam que o modo de aprender a profissão, conforme a perspectiva da imitação será a partir da observação, imitação, reprodução e, às vezes, reelaboração dos modelos existentes na prática consagrados como bons.

O estágio de observação na escola permite-nos a apreensão da realidade institucional, e se dá inicialmente por uma busca proporcionada pelo olhar, no momento em que aquilo que julgamos aparentemente normal passa a ser enxergado de forma diferente e curiosa. É neste momento que o mundo passa a ser constantemente explorado e desvelado, gerando novas formas de compreensão e de intervenção por parte da humanidade. (LIMA, 2012, p. 68).

Os Estágios II (Ensino Fundamental) e IV (Ensino Médio) são estágios de regência de sala de aula, elaboração e desenvolvimento de projetos, totalizando uma carga horária de 520h/s. Essa carga horária é dividida igualmente entre as atividades internas desenvolvidas no Campus em horário normal de aula e em atividades no campo de estágio, desenvolvidas como parte do mesmo processo formativo. As atividades internas são desenvolvidas pelos professores orientadores do estágio e objetivam preparar o estagiário para as atividades docentes por meio de reflexões sobre as tendências do ensino da Matemática e questões que envolvam o cotidiano das atividades docentes, como: a) gestão da sala de aula; b) organização dos conteúdos; c) análise de livros didáticos; d) estratégias de ensino; e) elaboração e material didático no Laboratório de Educação Matemática (LEM), dentre outras.

Quanto às atividades externas, no lócus do exercício docente, devem ser acompanhadas pelos professores regentes da disciplina de matemática, que buscam proporcionar aos licenciandos momentos em que possam acompa-

Olh@ res, Guarulhos, v. 1, n1, p. 30-324, maio 2013. 
nhar o cotidiano escolar durante o ano letivo, como: a) planejamento curricular; b) encontros pedagógicos; c) reuniões e encontros de organismos colegiados (Conselho Escolar, Associação de Pais e Mestres, dentre outros), e, d) as atividades em sala de aula. Estas devem ser executadas pelos estagiários depois de planejadas e analisadas pelos professores regentes da disciplina.

As atividades do estágio realizam-se no IFCE campus Cedro e em escolas de Educação Básica das redes públicas ou particulares da Região Centro Sul do Estado do Ceará, as quais estão situadas nos municípios de Cedro, Iguatu, Várzea Alegre, Icó, Lavras da Mangabeira, Orós e Cariús e que oferecem Ensino Fundamental e Médio.

Com o objetivo de discutir o Estágio Supervisionado em matemática como espaço de desenvolvimento da epistemologia da prática docente, procurouse analisar o percurso, as experiências vividas durante as atividades de estágio no semestre 2009.2, tendo como referência as discussões e debates realizados em sala de aula, os registros escritos e os relatórios de estágio entregues ao final da disciplina.

Os sujeitos da pesquisa foram alunos regularmente matriculados no componente curricular Estágio III, conforme apresentado no quadro abaixo.

Quadro 2 - Caracterização dos estagiários no Componente Curricular de Estágio III no semestre 2009.2

\begin{tabular}{|c|c|c|c|c|c|}
\hline Semestre Letivo & \multirow{2}{*}{ Componente Curricular } & \multirow{2}{*}{ Semestre } & \multirow{2}{*}{ Turno } & \multicolumn{2}{|c|}{ Número de alunos } \\
\cline { 4 - 6 } & & & & Masculino & Feminino \\
\hline 2009.2 & Estágio III & S7 & Manhã & 05 & 08 \\
\hline Total de alunos & & & \multicolumn{1}{|c|}{$\mathbf{1 3}$} \\
\hline
\end{tabular}

Fonte: Diário de classe e Relatório final de estágio.

Os estagiários serão identificados pelas siglas E1, E2, E3, ... E13. Estes alunos realizaram seus estágios em escolas públicas da rede estadual, em salas de Ensino Médio e constaram de observação participante de aulas. Além das aulas, os estagiários acompanharam e participaram de atividades como: planejamento da disciplina, reunião de pais e mestres, encontros pedagógico, rotina de bibliotecas e laboratórios de informática, dentre outras.

Os alunos cumpriram todas as exigências necessárias e apresentaram uma postura reflexiva e investigativa em relação às experiências vivenciadas, desenvolvendo saberes pertinentes ao exercício da docência em matemática,

Olh@ res, Guarulhos, v. 1, n1, p. 303-324, maio 2013. 
compreendendo o Estágio Supervisionado como o espaço em que "[...] o futuro profissional toma o campo de atuação como objeto de estudo, de investigação, de análise e de interpretação crítica, embasando-se no que é estudado nas disciplinas do curso" (PASSERINI, 2007, p. 30).

\section{Análise e discussão dos resultados}

A Sociedade Brasileira de Educação Matemática (2003) assegura que as atividades de Estágio Supervisionado desempenham papel central nos cursos de formação docente, evidenciando que ao invés de constituírem espaços isolados, fechados em si mesmos, devem impregnar toda a formação com os saberes socialmente elaborados pelas trocas simbólicas de sala de aula, em que os licenciandos vão colocando em uso os conhecimentos teóricos que aprenderam, ao tempo que mobilizam outros, de diferentes naturezas e advindos de diferentes fontes, nos diferentes tempos e espaços curriculares vividos no interior da escola.

As discussões presentes nesta comunicação foram coletadas durante o semestre 2009.2, quando se realizaram as atividades inerentes ao componente curricular Estágio III, cujas atividades constituíam-se em observação e participação nas aulas do Ensino Médio. As atividades compreenderam estudos e discussões em sala de aula sobre referenciais teóricos voltados para a prática de ensino em matemática, relato de experiências apresentados em rodas de conversa na sala de aula e os relatórios de estágio como requisito para a conclusão da disciplina. $\mathrm{Na}$ primeira aula, no IFCE/Campus Cedro, constatou-se que os licenciandos cursavam o sétimo semestre da graduação, num total de treze alunos, dos quais cinco do sexo masculino e oito do sexo feminino.

Dentre os principais referenciais teóricos abordados no componente curricular, destacam-se: a) a sala de aula - contribuições da prática de ensino; b) a dimensão técnica da prática docente; c) a metodologia enquanto ato político da prática educativa; d) a relação teoria-prática na formação do educador, e, finalmente, e) a formação para a complexidade do ofício de professor. Esses referenciais foram trabalhados de forma articulada, estabelecendo relação com as observações feitas no lócus do estágio.

Olh@res, Guarulhos, v. 1, n1, p. 30-324, maio 2013. 
O processo de análise dos relatos e dos dados compreendeu a verificação dos registros dos alunos em relação à relevância do estágio como campo do conhecimento que articula teoria e prática na perspectiva de ensinar a docência. O relato a seguir, evidencia a primeira impressão que a maioria dos alunos conduz consigo antes de se defrontarem com a aprendizagem inicial e continua dos saberes necessários para o exercício da docência.

\begin{abstract}
Inicialmente pensei que o Estagio Supervisionado era uma disciplina que não tinha muita importância e que não precisaríamos desta, pois já sabíamos de nossa profissão, então não havia necessidade de observar os profissionais da área. No decorrer do curso mudei de opinião, pois notei a grande importância do estágio. Percebi que através da observação podemos "comparar" o que vivenciamos no nosso dia a dia em sala de aula, enquanto formandos, a realidade de alunos do Ensino Fundamental e Médio. Ainda podemos nos colocar no papel do professor observado e analisar o que gostaríamos de absorver desse profissional, ou algo que jamais utilizaríamos. (ESTAGIÁRIO 6).
\end{abstract}

Em alguns instantes outros alunos compartilham a mesma compreensão em relação ao estágio. Isso tende a mudar a partir do instante que o licenciando observa, discute e reflete a dinâmica da atividade docente, como ofício que exige pesquisa sobre a prática para se desenvolver diferentes formas de pensar, de compreender, de agir e de lidar com os problemas que ocorrem no fazer didático do professor de matemática. A esse respeito o Estagiário 6, assegura que "[...] é através do estágio que podemos tomar a decisão, fazer nossa escolha em ser ou não ser professor. Podemos nos identificar com a profissão ou notar que essa não é nossa área”. Ressalta ainda que:

[...] ao realizar o estágio de observação notei a importância da inovação, onde o professor tem que estar em constante mudança, pesquisa. Ainda percebi que para que haja um bom desempenho na atuação do professor é necessário que ele desenvolva sua teoria de maneira descontraída e séria ao mesmo tempo. E isso só é possível se ele conseguir transpor seu conhecimento de maneira segura, ou seja, se ele tiver domínio de seu saber. A teoria e a prática precisam andar juntas, pois não é possível colocar em prática o que não se sabe. (ESTAGIÁRIO 6).

De fato, não se ensina aquilo que não se sabe. Por isso, faz-se necessário que o professor esteja consciente da sua incompletude, compreendendo que há muito que aprender, principalmente, no exercício da profissão docente, com os alunos, com os colegas de trabalho e com as famílias responsáveis pelos alunos. Assim, compreender o estágio como um tempo específico de ensino e de aprendizagem é indispensável, pois somente o conhecimento adquirido em sala de aula durante o curso de formação inicial em matemáti-

Olh@ res, Guarulhos, v. 1, n1, p. 303-324, maio 2013. 
ca não é suficiente para a formação do futuro educador. É preciso o exercício em atividades práticas.

No estágio, acompanhando a rotina da sala de aula, o licenciando tem a oportunidade de acompanhar os diversos fenômenos de ensino e aprendizagem, os quais se dão desde o contrato didático que, enquanto conjunto de expectativas, levanta entre os protagonistas do processo (professor $\mathrm{x}$ alunos e alunos $\mathrm{x}$ professor), em função da produção do conhecimento, até obstáculos epistemológicos que são compreendidos como as dificuldades inerentes ao saber científico e ao saber que se pretende ensinar.

A sala de aula, além de um ambiente onde se ensina e se aprende é também um universo que propõe aperfeiçoamento e formação profissional em serviço, tomando como referência situações e experiências vividas no cotidiano da sala de aula e no fazer pedagógico do professor. Dessa maneira, a sala de aula é um espaço formador para alunos e para professores. A esse respeito Garrido (2001, p. 125) apresenta

[...] a sala de aula como espaço formador para o aluno. Espaço em que ele aprende a pensar, elaborar e expressar melhor suas ideias e a ressignificar suas concepções, ao ser introduzido no universo dos saberes teoricamente elaborados e nos procedimentos científicos de análise, interpretação e transformação da realidade.

No Estágio III uma das atividades básicas é a observação em turmas da última etapa da Educação Básica - Ensino Médio. No decorrer do mesmo, o Estagiário 12 descreveu a postura da professora regente frente à sala de aula, relatando seu desempenho pedagógico, que embora utilizando recursos materiais básicos conseguiu ministrar boas aulas.

[...] o professor regente agia sempre com bastante tranquilidade, demonstrando segurança e um bom relacionamento com a turma. Estava atento, para que os alunos não se excedessem em conversas e brincadeiras que causassem tumulto, sempre agindo desta forma deixava os alunos tranquilos. O material utilizado durante as aulas foram: o livro didático, quadro branco e pincel. No entanto, o professor conseguiu realizar um bom trabalho e transmitir com eficiência os assuntos ministrados, demonstrando muita segurança e domínio dos conteúdos matemáticos que abordava. (ESTAGIÁRIO 12).

Olh@ res, Guarulhos, v. 1, n1, p. 30-324, maio 2013. 
Ainda no tocante à prática em sala de aula, outro estagiário faz referência ao desempenho do professor observado, evidenciando sua preocupação com a aprendizagem dos alunos, como finalidade do fazer docente.

A professora regente ministra suas aulas com bastante clareza e com muita calma para facilitar a compreensão de todos os alunos, apesar de alguns se mostrarem impacientes e desatentos. Utiliza bem todos os materiais que utiliza em sala de aula, domina muito bem os conteúdos expostos, mantém um laço de amizade muito grande com todos os alunos e tem uma grande preocupação com o aprendizado de todos. (ESTAGIÁRIO 8).

Desenvolver a atividade docente nos tempos atuais tem sido, cada vez mais, desafiador, pois ser professor não é simplesmente ir à sala e passar o conteúdo. Nos bastidores da profissão, o professor precisa preparar-se para ministrar uma boa aula, tornando o conhecimento acessível ao aluno, propiciando os meios necessários para que o educando seja capaz de produzir conhecimento, mantendo a curiosidade como dispositivo para novas aprendizagens. Assim sendo, para o desenvolvimento de um bom trabalho o professor precisa de horas para estudar, planejar aulas, pesquisar, estar atento ao mundo, observar bastante e em sala de aula no exercício da docência, ter a possibilidade de aprender por meio da prática. A esse respeito Ghedin (2010) aponta que a reflexão sobre a prática constitui em seu questionamento com vistas a intervenções e mudanças.

As observações de práticas feitas pelos estagiários revelam-se como uma importante atividade na formação inicial de futuros professores de matemática. O acompanhamento dessas atividades, de fato, propicia ao professor em formação inicial a oportunidade de verificar o contexto educacional, político e social da escola, analisando as diferentes realidades do campo escolar e estabelecendo um laço de interação entre o educador, o educando e o fazer docente.

No contexto da prática docente, o professor precisa estar preparado para lidar com diferentes situações que ocorrem no cotidiano da sala de aula. Um problema constante é o desinteresse dos alunos em relação aos conteúdos matemáticos, ficando o professor na incumbência de sensibilizar aos educandos para a importância desses conteúdos na formação cidadã dos mesmos. A esse respeito, em seus relatórios, os estagiários apontaram que

Olh@ res, Guarulhos, v. 1, n1, p. 303-324, maio 2013. 
essas situações ocorreram nas salas observadas. O Estagiário 2 registrou que “[...] a professora regente demonstrou preocupação e interesse pela aprendizagem dos alunos, ela tentava a todo instante chamar a atenção deles para os conteúdos estudados em sala, porém existem aqueles que não tinham interesse algum”. Já os Estagiário 7, 10 e 8 fizeram os seguintes registros:

Ao expor o conteúdo, o professor regente mostrou ter conhecimento matemático específico, expondo o conteúdo de maneira clara. Porém a turma é numerosa, com 44 alunos e bastante heterogênea, formada por jovens interessados, participativos, mas com algumas dificuldades nesta disciplina e alguns com índice de aprendizagem elevado, mas também tinha aqueles desinteressados, que não mostravam nenhum interesse na aula, sentavam-se no fundo da sala pra conversar. Então o professor procurava envolvê-los, fazendo com que participassem, indagando sobre o conteúdo e suas dificuldades. (Estagiário 7).

Todo instante a professora manifestou competência quanto ao domínio do conteúdo estudado, ela demonstrou clareza nas explicações, procurando meios mais fáceis de explicar o assunto estudado. A mesma respondia as perguntas dos alunos e tirava-lhes as dúvidas, estabelecendo uma relação harmoniosa com os alunos que a respeitavam e a atendiam quando pedia que fizessem silêncio durante a exposição da aula. (Estagiário $10)$.

Durante a exposição do conteúdo programático em alguns momentos, alguns alunos ficaram dispersos, mostrando pouco interesse com relação aos assuntos vistos, mas nada que pudesse impedir o êxito e o trabalho do professor, que mesmo diante destas dificuldades manteve uma relação de cumplicidade e companheirismo com os alunos e demonstrou uma ótima postura, provando que tinha o domínio da turma, sem perder o respeito ou a autoridade dentro da sala de aula. (Estagiário 8).

Do exposto, é possível afirmar que o estágio é um espaço simultâneo de aprendizagem e formação sobre a docência, enquanto atividade profissional do professor e do futuro professor. Acompanhando e observando o cotidiano do professor, sua prática, as intervenções pedagógicas que propõe em sala de aula e outras atividades de incumbência do professor. Assim, o licenciando tem a possibilidade de conceber o fazer docente não como uma ação que acontece de forma isolada, mas como um processo de aprendizagem permanente no qual o desejo de aprender sempre é condição para melhorar sua prática pedagógica.

Como apontado anteriormente pelos estagiários, o professor trabalha em contextos compostos por alunos com vontade de aprender e também por

Olh@ res, Guarulhos, v. 1, n1, p. 30-324, maio 2013. 
quem não manifestam esse interesse. Essa realidade é presente em todas as salas de aula, no decorrer do Estágio III. Quanto ao desinteresse de alguns alunos em relação às aulas de matemática o Estagiário 10 mostrou que isso ocorre "[...] talvez porque a metodologia do professor estava centrada, frequentemente, na exposição oral de conteúdos por meio de explicações com ênfase na resolução de exercícios, utilizando como recurso didático o quadro branco, pincel e livro didático".

É importante destacar que no atual contexto, o ensino de matemática ainda é marcado por metodologias tradicionais, dificultando a sua aprendizagem. É preciso aprender a expressar de forma diferenciada e objetiva a transmissão e a produção de conhecimentos matemáticos com vistas a uma aprendizagem significativa por parte do educando. A esse respeito, Lorenzato (2006, p. 5) afirma que "[...] o professor que ensina com conhecimento conquista respeito, confiança e admiração de seus alunos".

O saber e o fazer do professor de matemática não se reduzem a uma fórmula dada na formação, antes são construídos ao longo de sua práxis educativa, pautados numa relação significativa com o saber e o saber fazer, em que os saberes coletivos mediados no conjunto da comunidade escolar assumem papel relevante. Dessa forma, ensinar e aprender na contemporaneidade exige novas formatações que assegurem mudança na tentativa de ensinar e aprender Matemática de forma nova, levando o professor a ressignificação de sua prática. Braumann (2002, p. 5) assegura que:

[...] aprender Matemática não é simplesmente compreender a Matemática já feita, mas ser capaz de fazer investigação de natureza matemática (ao nível adequado a cada grau de ensino). Só assim se pode verdadeiramente perceber o que é a Matemática e sua utilidade na compreensão do mundo e na intervenção sobre o mundo.

Convictos da relevância do estágio para a formação do professor de matemática, os licenciandos não deixaram de enfatizar que o estágio propiciou conhecer a realidade da educação e incentivou o desenvolvimento de novas formas de ensinar e aprender o exercício da docência. Elencaram, ainda em seus relatos que as experiências propiciadas pelo Estágio oportunizou o desenvolvimento de conhecimentos, de habilidades e de competências pertinentes ao desempenho da profissão docente, bem como uma metodologia comprometida com a problemática do campo de estágio,

Olh@res, Guarulhos, v. 1, n1, p. 303-324, maio 2013. 
contemplando os fundamentos teóricos e metodológicos aprendidos em sua formação inicial e uma postura crítica e ética no estagiário frente à sua atuação docente, avaliando-a e redimensionando-a.

O Estagio Supervisionado III nos trouxe uma real compreensão do dia a dia da sala de aula e nos fez compreender a importância do trabalho docente, tendo como espaço de atuação profissional a escola e, especialmente, a sala de aula. As atividades possibilitaram um contato direto com professores experientes, onde aprendemos muito com os mesmos, não esquecendo que alguns nos apresentaram velhas praticas e costumes frente ao processo de ensino aprendizagem de matemática. Sem nenhuma duvida o estagio é muito importante para a nossa formação como professores e tem como objetivo principal a formação de um professor que esteja consciente de que sua pratica envolva um comportamento de observação reflexão critica e reorganização das suas ações. (ESTAGIÁRIO 13).

É possível perceber que as atividades de estágio propiciam ao licenciando em matemática, conhecimento do seu futuro campo de atuação profissional, percebendo os limites, as possibilidades e as peculiaridades do âmbito escolar, sendo também, espaço para se verificar as competências adquiridas para a efetivação da prática profissional. Tardif (2002, p. 86) aponta que "[...] a tomada de consciência dos diferentes elementos que fundamentam a profissão e a integração na situação de trabalho levam à construção gradual de uma identidade profissional".

Nesta caminhada, destaca-se a prática como um exercício específico constituído de ações que permitem a realização de uma determinada tarefa objetivando o alcance de resultados específicos. Assim, o Estágio em Matemática é um campo teórico e prático que visa propiciar ao licenciando experiências as quais são vivenciadas na instituição de formação inicial e no lócus do estágio. Durante o desenvolvimento das atividades, procura-se refletir com os licenciandos sobre a formação profissional, com uma visão crítica da matemática, na tentativa de formar um professor que seja capaz de analisá-la e sobre ela refletir, sendo capaz de ensinar com habilidade para estimular a cooperação entre os alunos, utilizando o confronto de ideias para formulação de argumentos e validação com alunos do Ensino Fundamental e Médio.

O professor que pretende se formar deve estar consciente das suas limitações e investir em sua formação continuada, refletindo sobre sua prá-

Olh@ res, Guarulhos, v. 1, n1, p. 30-324, maio 2013. 
tica como educador, pois, de acordo com Fiorentini \& Castro (2003, p. 127), “[...] sem reflexão, o professor mecaniza sua prática, cai na rotina, passando a trabalhar de forma repetitiva, reproduzindo o que está pronto e o que é mais acessível, fácil ou simples". Com o exercício da reflexão sobre a própria prática, o professor torna-se um analista crítico da realidade, sendo capaz de resolver problemas.

Ao realizar o estágio notei a importância da inovação, onde o professor tem que estar em constante mudança, pesquisa. Ainda percebi que para que haja um bom desempenho na atuação do professor é necessário que ele desenvolva sua teoria de maneira descontraída e séria ao mesmo tempo. E isso só é possível se ele conseguir transpor seu conhecimento de maneira segura, ou seja, se ele tiver domínio de seu saber. A relação teoria-prática tem que andar juntas, pois não é possível colocar em prática o que não se sabe e se alguém conhece algo que não pode repassar de qualquer maneira. (ESTAGIÁRIA 6).

Além da observação e participação na dinâmica do cotidiano da sala de aula, os estagiários também se voltaram para a análise do espaço escolar, diagnosticando e caracterizando a rotina da instituição. Dentre estes espaços e tempos escolares que oportunizam aos licenciandos em matemática o desenvolvimento de saberes sobre a prática do professor no Ensino Médio, destaca-se o planejamento como processo de tomada de decisões que deve ser compreendido como “[...] instrumento que orienta a educação, como processo dinâmico e integrado de todos os elementos que interagem para a consecução dos objetivos, tanto os do aluno, como os da escola" (PADILHA, 2005, p. 33). Sobre o planejamento, os relatos abaixo apontam o posicionamento dos estagiários.

O planejamento é uma atividade de reflexão acerca das ações que pretendemos desenvolver. A ação de planejar é inerente ao ser humano, portanto, planejamos porque traçamos metas e queremos alcançar resultados. Ao professor cabe planejar porque a atividade de ensinar exige tomada de consciência e deve ter como referência constante os alunos e suas condições de aprendizagem. (ESTAGIÁRIO 13).

Durante os planejamentos por área, os professores de matemática procuraram programar as ações a serem desenvolvidas em sala de aula, refletindo sobre os conteúdos e métodos de ensino, analisando as condições dos alunos, sem deixar de fora a realidade social, o nível de preparo e as condições socioculturais de cada um. (ESTAGIÁRIA 6).

O planejamento da escola acontece da seguinte forma: mensal e semanal. Mensal com todos os professores da escola e semanal com os professores da disciplina de matemática, o qual acontece com o apoio do coordenador pedagógico, tendo como objetivo a integração entre todos para juntos discutirem experiências e buscarem soluções para os problemas encontrados e mostra o que deu certo no contexto de sala de aula. (ESTAGIÁRIA 12).

Olh@res, Guarulhos, v. 1, n1, p. 303-324, maio 2013. 
Para Lima (2008), a observação do contexto e a investigação do cotidiano escolar abrem um leque de outras questões de investigação/intervenção que podem se constituir como aprendizagem da profissão docente. Portanto, as atividades desenvolvidas no percurso do estágio, constituem-se em oportunidade de descobrir alternativas para desenvolver a prática docente e permitir aos estagiários se reconhecerem como aprendizes da profissão docente.

\section{Conclusão}

A atuação docente em um curso de formação inicial para professores de matemática tem permitido trabalhar com o componente curricular de Estágio Supervisionado, o qual não se reduz a um simples acréscimo curricular de uma dimensão teórico-prática. Neste estudo, percebeu-se que o estágio é um espaço no qual o discente desenvolve seus conhecimentos junto às instituições educacionais, relacionando teoria e prática e desenvolvendo uma epistemologia da prática profissional que se (re)constrói mediante suas experiências e aprendizados no exercício da docência.

Verificou-se, por meio da observação e falas dos estagiários, que com o estágio é possível construir diferentes olhares e resignificar a docência em matemática, sendo o aprendizado consequência de sua ação docente, mediatizada pela reflexão crítica sobre a própria prática. Analisar e refletir criticamente a prática educativa desenvolvida na escola deve ser missão de todo professor, que tem como referência a aprendizagem de seus alunos, bem como sua formação permanente para ensinar cada vez melhor.

Os estudos comparativos entre teoria estudada e prática observada, consolidaram-se em elementos de referência para significativas discussões em sala de aula, oportunizando aos estagiários a socialização e troca de experiências sobre práticas pedagógicas, práticas de gestão escolar, planejamento de atividades didáticas, produção e utilização de material didático, dentre outros. Nessa configuração, a troca de experiência permite ao futuro profissional, mais preparo para atuar no ensino de matemática e lidar com a complexidade da realidade escolar.

Olh@ res, Guarulhos, v. 1, n1, p. 30-324, maio 2013. 
Veiga (2008, p. 20) afirma que o trabalho docente é "[...] uma atividade profissional complexa, pois requer saberes diversificados". Por essa razão, é preciso oportunizar ao futuro professor a experimentação de diferentes conhecimentos para exercer seu ofício com significado, pautando-se em princípios pedagógicos que legitimem o seu fazer profissional com eficácia. Sendo assim, é necessário formar professores inseridos numa instituição de educação básica, capazes de conviver com uma diversidade de saberes oriundos de seus alunos, fruto de contextos econômicos e sociais, que interferem no processo de aprendizagem.

O Estágio Supervisionado expressa sua relevância na formação inicial do professor, que, conforme Pimenta e Lima (2004), é fundamental ao propiciar ao aluno um momento específico de aprendizagem e possibilita uma visão crítica da dinâmica das relações existentes no campo institucional, enquanto processo efervescente, criativo e real do fazer educativo.

Do exposto, pode-se afirmar que as ações desenvolvidas no Estágio III, nos diferentes espaços educativos, buscou integração dos diversos atores educativos envolvidos, promovendo aprendizagem em relação à formação do docente para o ensino de matemática, constituindo-se num saber experiencial articulado com o cotidiano da prática docente.

Os dados revelam que o estágio oportunizou aos estagiários desenvolver uma epistemologia da prática docente para o exercício da profissão, em que a análise, a articulação e a reflexão crítica lhes possibilitaram assumir posturas diferenciadas em relação à prática tradicional e conteudista de ensino em matemática. Além disso, tomaram consciência de que a sala de aula é um espaço nutridor de relações e aprendizagens que propicia diferentes saberes com repercussão reflexiva sobre o seu desenvolvimento profissional; sobre questões relacionadas a dinâmica da sala de aula; sobre as metodologias que devem ou não ser utilizadas na prática de ensino, concebendo a escola como espaço dinâmico de produção de conhecimento, logo espaço também de sua formação como educadores.

Olh@res, Guarulhos, v. 1, n1, p. 303-324, maio 2013. 


\section{Referências}

ANDRADE, A. M. O Estágio Supervisionado e a Práxis Docente. In: SILVA, M. L. S. F. (Org.). Estágio Curricular: Contribuições para o Redimensionamento de sua Prática. Natal: Ed. UFRN, 2005.

BARREIRO, I. M. F. \& GEBRAN, R. A. Prática de Ensino e Estágio Supervisionado na Formação de Professores. São Paulo: Avercamp, 2006.

BRASIL. Ministério da Educação - Conselho Nacional de Educação. Parecer N. ${ }^{\mathbf{0}}$ : CNE/CP 28/2001. Disponível em: http://portal.mec.gov.br/cne/arquivos/pdf/028.pdf. Acesso em: 20 de set. de 2012.

BRAUMANN, C. Divagações sobre Investigação Matemática e o seu papel na Aprendizagem da Matemática. In: PONTE, J. P. [et al] Atividades de Investigação - na aprendizagem da matemática e na formação dos professores. Lisboa: Secção de Educação Matemática da Sociedade Portuguesa de Ciências da Educação, 2002.

FIORENTINI, D. \& CASTRO, F. C. de. Tornando-se professor de matemática: o caso de Allan em prática de ensino e estágio supervisionado. In: FIORENTINI, D. (Org.). Formação de professores de matemática: explorando novos caminhos com outros olhares. Campinas, SP: Mercado de Letras, 2003. p. 121- 156.

FREIRE, P. Pedagogia da Autonomia: Saberes necessários à prática educativa. Rio de Janeiro: Paz e terra, 1996.

GARRIDO, E. Sala de aula: Espaço de construção do conhecimento para o aluno e de pesquisa e desenvolvimento profissional para o professor. In CASTRO, A. D. (Org.); CARVAlHO, A. M. P. (Org.) . Ensinar a Ensinar: Didática para a Escola Fundamental e Média. São Paulo: Pioneira Thomson Learning, 2001.

GHEDIN, E. Professor reflexivo: da alienação da técnica à autonomia da crítica. In: PIMENTA, S. G. GHEDIN, E. (Orgs) Professor reflexivo no Brasil: gênese e crítica de um conceito. São Paulo: Cortez, 2010.

IFCE. Instituto Federal de Educação, Ciência e Tecnologia do Ceará - Campus de Cedro. Proposta Pedagógica do Curso de Licenciatura em Matemática. Cedro-CE, 2007. (Mimeo).

LIBÂNEO, J. C. Organização e gestão da escola: teoria e prática. Goiânia: Alternativa, 2001.

Olh@ res, Guarulhos, v. 1, n1, p. 30-324, maio 2013. 
LIMA, M. C. L. Reflexões sobre o estágio/prática de ensino na formação de professores. Rev. Diálogo Educ., Curitiba, v. 8, n. 23, p. 195-205, jan./abr. 2008.

LIMA, M. S. L. Estágio e aprendizagem da profissão docente. Brasília: Liber Livro, 2012.

LORENZATO, S. Para aprender matemática. Campinas: Autores Associados, 2006.

PADILHA, P. R. Planejamento Dialógico: Como construir o projeto político-pedagógico da escola. São Paulo: Cortez; Instituto Paulo Freire, 2005.

PASSERINI, G. A. O estágio supervisionado na formação inicial de professores de matemática na ótica de estudantes do curso de licenciatura em matemática da UEL. 121 f. Dissertação - Universidade Estadual de Londrina. Londrina: UEL, 2007.

PIMENTA, S. G. \& LIMA, M. S. L. Estágio e docência. São Paulo: Cortez, 2012.

PIMENTA, S. G. \& LIMA, M. S. L. Estágio e docência: diferentes concepções. Revista Poíesis -Volume 3, nº 3, p.5-24, 2006.

SBEM. Subsídios para a Discussão de Propostas para os Cursos de Licenciatura em Matemática: Uma contribuição da Sociedade Brasileira de Educação Matemática. São Paulo, 2003, 43p.

TARDIF, M. Saberes docentes e formação profissional. Petrópolis, RJ: Vozes, 2002.

VEIGA, I. P. A. Docência como atividade profissional. In: VEIGA, I. P. A. \& D’ÁVILA, C. M. (Orgs) Profissão docente: Novos sentidos, novas perspectivas. Campinas - SP: Papirus, 2008.

ZEICHNER, K. Repensando as conexões entre a formação na universidade e as experiências de campo na formação de professores em faculdades e universidades. Revista Educação: Santa Maria, v. 35, n. 3, p. 479-504, set./dez. 2010.

WIELEWICKI, H. G. Prática de Ensino e Formação de Professores: Um Estudo de Caso sobre a Relação Universidade-Escola em Cursos de Licenciatura. Tese. UFRGS - Porto Alegre, RS, 2010. 